\title{
Elimination of Misconduct in Manual Counting Process as an Improvement of Inventory Accuracy in A Manufacturing Company
}

\author{
Iman Haddad Qaisara Dhia Mohd Mahzan'1, Khai Loon Lee ${ }^{1}$ \\ ${ }^{1}$ Faculty of Industrial Management, Universiti Malaysia Pahang, 26600 Pahang, Malaysia.
}

ABSTRACT - Managing inventory is crucial especially for manufacturing companies as it has a direct influence on profits of the company. In order to have an efficient inventory management, inventory accuracy need to be achieved and this can be achieved by leveraging technologies and techniques that can minimize the human error. The objective of this study is to investigate the factors affecting inventory inaccuracy in Factory 21 of $A B C$ manufacturing company. This study reveals that the inventory inaccuracy is influenced by the order received in the factory, which is due to the human misconduct during the manual counting process of cartons on pallet. This paper proposes the deployment of Arduino sensor network system in automating the carton counting process. The findings for this study show that the automation system able to improve the inventory record accuracy in $\mathrm{ABC}$ manufacturing company.

\author{
ARTICLE HISTORY \\ Received: 13-1-2021 \\ Revised: 20-2-2021 \\ Accepted: $26-2-2021$

\section{KEYWORDS} \\ Inventory accuracy \\ Misconduct \\ Arduino sensor network \\ system \\ Counting sensor \\ Manufacturing
}

\section{INTRODUCTION}

\section{Background of Study}

Manufacturing industry is one of the rising sectors in Malaysia. According to Department of Statistics Malaysia (DoSM) (Department of Statistics Malaysia, 2020), Malaysia's manufacturing industry recorded a growth of 3.7\% in September 2020 compared to the previous year. Despite the fact that Covid-19 pandemic affects the world's economy, Malaysia's manufacturing industry is currently in the revival and recovery process (The Edge Markets, 2020). Due to this, an effective inventory management system is required by manufacturing companies more than ever. Inventory management is an essential component in supply chain management and plays a key role in a manufacturing company.

In the manufacturing industry, inventory control is essential and considered as one of the key management areas as inventory has a direct influence on profits of a company and the company could also suffer from losses due to ineffective inventory system (Atnafu \& Balda, 2018; Mohamad et al., 2016). To manage inventory effectively and efficiently, a thorough analysis is needed so that the operations in a company can run smoothly and reduce the overall production cost. By having good inventory management, a company will be able to generate more revenue. Thus, improving the performance of the company (Mohamad et al., 2016).

\section{Research Problems}

One of the aspects of a good inventory management system is to have a high accuracy of inventory record which means the variances between the physical and virtual inventory are small (Chuang \& Oliva, 2015; Drakaki \& Tzionas, 2019; Hachem et al., 2016) Nevertheless, inventory record inaccuracy appears to be a significant problem across the industries especially in the retail and manufacturing industries (Dai et al., 2016; Karim et al., 2018; Rekik et al., 2019).

Inventory record inaccuracy is also one of the serious problems in Factory 21 of ABC Manufacturing Company, especially for finished goods. When customers make orders, the order will be produced and packed according to customer preferences. The order that has been packed into cartons will be palletized, and arrange on the pallet. Then, the palletized goods will be kept either in the factory's warehouse or in one of the centralized the warehouses in ABC Manufacturing Company, before the goods are being shipped to the point of destination. Nevertheless, the pallets will be assigned with a pallet slip consisting of the information related to the products on the pallet. The information includes the brand, product, and the quantity of the cartons on the pallet. However, workers will also count the cartons on each pallet manually before generating the pallet slip. Due to this, sometimes, human errors occur. For instance, miscount of the cartons on the pallet resulted in the mismatch of thenumber in the inventory system and the physical inventory.

Company profits and losses are heavily affected by inventory management (Mohamad et al., 2016). Efficient inventory management influences the financial performance of a company positively (Sunday \& Joseph, 2017). Mainly in manufacturing companies, inventory contributes to a major part of the company's assets. Hence, inventory needs to be managed effectively as having an optimal level of working capital management can maximize the company's profit (Prempeh \& Amankona 2020).Research Questions 
In general, this study investigates the factors affecting inventory inaccuracy in ABC Manufacturing Company. Specifically, this study has questions listed below:

1. What are the factors affecting inventory record inaccuracy in ABC Manufacturing Company?

2. How to improve the inventory record accuracy in ABC Manufacturing Company?

\section{Research Objectives}

In general, this study aims to answer the questions on investigating the factors affecting inventory inaccuracy and propose a method to improve the inventory record accuracy in ABC Manufacturing Company. Specifically, the objectives of this study are:

1. To investigate the factors affecting inventory record inaccuracy in ABC Manufacturing Company.

2. To propose an automation system to improve the inventory record accuracy in ABC Manufacturing Company.

\section{Scope of the Study}

Majority of the studies related to inventory control are focusing on the causes and impact of inventory record accuracy in the manufacturing and the retail sector located in western countries and Africa (Dai et al., 2016; Karim et al., 2018; Prempeh \& Amankona, 2020; Rekik et al., 2019). Therefore, this study attempts to bridge the gap and examine the causes of inventory record inaccuracy in a manufacturing company in Malaysia. Besides, several studies have addressed the deployment of cycle counting and RFID technology in improving inventory accuracy (Drakaki \& Tzionas, 2019; Karim et al., 2018; Tejesh \& Neeraja, 2018). Hence, this study seeks to propose an implementation of Arduino sensor network system in inventory counting to improve inventory accuracy.

\section{Significance of the Study}

This study will be focusing on designing a prototype using Arduino sensor network system, which is used to automate the process of counting the inventory. The ultrasonic sensor is used to count the cartons that pass through the conveyor belt before being arranged on a pallet. The data captured by the Ultrasonic sensor is collected by Arduino Uno and send to the database for record purposes (Carvalho et al., 2016; Saxena et al., 2020). Workers can refer to the database to determine the number of cartons palletized on a pallet. With this, manual transaction errors can be avoided, and workers' misconduct can be minimized. Thus, improving the company's inventory record accuracy. Indirectly, improved efficiency and effectiveness of manpower and process lead time.

\section{LITERATURE REVIEW}

\section{Inventory Management and Inventory Record Inaccuracy}

Inventory management is directly proportional to the company's performance. Through hypothesis testing, Syed Mohamad et al. (2016) proves that the Return on Asset (ROA) of a company is indirectly proportional to the inventory days. The inventory days negatively affects the ROA. ROA is an accounting-based measure to measure the company's performance. Hence, inventory management influences the company's performance (Mohamad et al., 2016). This is further supported by Sunday and Joseph (2017) with a conclusion, in which inventory management has a significant role to play in the corporate financial performance of businesses. Therefore, the company must maintain a sufficient level of inventory to maximize profitability and reduce the inventory costs associated with maintaining unnecessary stock in warehouses (Sunday \& Joseph, 2017).

Inventory record inaccuracy is an error that happens when the inventory record does not match the physical inventory. These anomalies are usually found in inbound transactions, shelving operations and outbound transactions. Due to these mistakes, the organization has to work with the incorrect information and make incorrect decisions that are often caused by shrinkage and transaction errors (Chuang \& Oliva, 2015; Okyay, 2014). There are several practices for inventory management that an organization can implement to minimize inventory record inaccuracy. For instance, the deployment of barcode and RFID tags to monitor and track inventory movement (Drakaki \& Tzionas, 2019; Qin et al., 2017; Talavera et al., 2015; Tejesh \& Neeraja, 2018). Besides, the implementation of enterprise resource planning technology for inventory management control system to keep an up-to-date inventory records and all records associated with managing the inventory (Mohamad et al., 2016) as well as cycle counting operation which is conducted periodically (Karim et al., 2018).

Cycle counting may perform daily, weekly, monthly, quarterly, or yearly depending on the company's policy itself. A cycle counting is a method of measuring the physical inventory and comparing the sum in the system with the record. The more regular the stock count, the more precise the stock quantity. The cycle counting method does require not only physical counting conducted by the workers but also the reconciliation for any discrepancies between physical and virtual inventory. Reconciliation will be carried out by the workers handling the inventory. It will then be checked and approved by the head of the department before being sent for adjustment to the Finance Department. Upon receiving approval, the system will be modified to ensure that the physical inventory and the virtual inventory match (Karim et al., 2018).

This study shows that many inventory management issues were due to inconsistency in the company's activities. The cycle counting operation was not adequately prepared and its standard operating procedures were incomplete. Furthermore, there is no division of duties for the person who collects the raw materials and incorporates the knowledge into the system. This can lead to potential errors at the earliest point that cannot be identified and avoided (Karim et al., 2018). Moreover, Qin et al. (2017) discuss the effect of inventory inaccuracy on the supply chain performance due to 
shrinkage and its impact on the bullwhip effect. The financial impacts of inventory inaccuracy do include not only the cost of direct inventory loss but also the growing holding and shortage costs at each point due to the dissemination of information inconsistency throughout the supply chain. When preventive measures are taken through RFID visibility, inventory inaccuracy can be minimized as well as reducing the cost associated with inventory inaccuracy (Qin et al., 2017). Therefore, instead of adjusting discrepancies found out during cycle counting, the organization can opt for preventive measures that can improve inventory record accuracy by deploying technology in counting, monitoring, and tracking the inventory. This concept reduces errors due to human involvement by including an automation system in operation.

\section{Internet of Things in Inventory Management}

Along with advancements, the possibilities of using the Internet of Things (IoT) technology are increasing. The IoT facilitates the attachment of previously unstable physical components to the network in the scope of warehousing systems, thereby controlling the storage facility and facilitating it. Inventories are especially troublesome components in each warehouse, such as manual inventory manipulation due to human-based inventory management. Nevertheless, by deploying sensors and linking them to the network, the sensors capture the real-time inventory data, significantly improving inventory management (Buntak et al., 2019). Data can be accessed remotely as the sensors connect to the internet and transmit it over the internet. This will improve the organization's productivity as IoT smartly links the actual warehouse environment to the digital environment. (Yerpude \& Singhal, 2018).

In terms of inventory records, the accuracy can be improved with the deployment of technologies such as RFID technology and IoT technology. Nevertheless, in order to maximize the benefits of implementing RFID technology in minimizing inventory record inaccuracy, all supply chain members must be aware of the inaccuracy and optimize their practices besides deploying RFID technology to minimize inventory inaccuracy. The benefits of RFID technology is more significant when the entire supply chain is considered (Qin et al., 2017). However, a study by Drakaki and Tzionas (2019) shows that the bullwhip effect is greater in the RFID-enabled supply chain as compared to the non-RFID-enabled supply chain. RFID-enabled supply chains are still subject to inventory inaccuracy, even in cases with low inventory error levels. Therefore, due to the existence of inventory inaccuracy, RFID-enabled data sharing supply chains in which all supply chain stages implementing RFID are more susceptible to bullwhip effect magnification (Drakaki \& Tzionas, 2019).

There are advantages offer by RFID, such as visibility and transparency of joint supply chain operations. However, a compromise between the advantages is the amplification of the bullwhip effect due to inventory inaccuracy. A study depicts that the distortion of order variance information indicates increased unrepresented demand uncertainty due to the inability to capture actual inventory level and thus increased stockout and backlog possibility and reduced service level in the non-RFID-enabled supply chain (Drakaki \& Tzionas, 2019). Hence, in this era of the Internet of Things, RFID technology and IoT technology should be implemented to provide inventory visibility and improve warehouse inventory management.

Several implementations of IoT technology in inventory management serving different functions depending on the organization's requirement or project depict that the deployment of IoT technology facilitates the improvement of warehouse inventory management. Tejesh and Neeraja (2018) discuss that the RFID technology fits the warehouse inventory management system as best as possible in tracking and locating products in a warehouse. The tag information is transmitted through a wireless Internet connection from the transmitter portion to open-source hardware. Based on the IoT architecture, the warehouse inventory management system is designed to monitor and track the items attached to the product information tags and their respective time stamps for further verification (Tejesh \& Neeraja, 2018). Furthermore, Velasco et al. (2019) propose a sensor network system that incorporates a standard refrigerator, microcontrollers, and a smartphone to create an inventory tracking system that can wirelessly track stocks inside the fridge by accessing an Android application (Velasco et al., 2019). Besides, Sowmya et al. (2018) illustrate the environmental factors that affect the quality of fruit storage and conventional means of protection and proposes a multi-parameter monitoring system based on WiFi, including gas sensors, temperature sensors, and humidity sensor. The goal is to facilitate the upgrade of the warehouse management system, contributing to the optimization of the environment for fruit storage and ensuring the healthy storage of fruits. Thus, preventing fruit waste and economic losses (Sowmya et al., 2018).

\section{THE CASE COMPANY}

ABC Manufacturing Company was established in 1991, and it is one of the largest glove manufacturers in the world. The headquarters of ABC Manufacturing Company located in Klang, Malaysia. ABC Manufacturing Company produces rubber gloves and non-glove products such as dental dams, exercise bands, sexual wellness products, household products, and the latest products manufactured by them are face masks. ABC Manufacturing Company currently has 47 factories with 750 production lines worldwide, which produce approximately 90 billion gloves per annum. Besides that, ABC Manufacturing Company also has marketing offices in countries like the USA, Germany, and Brazil. With 21,000 employees working in ABC Manufacturing Company, the company aims to continue producing high-quality gloves at an efficient low cost.

As one of the biggest glove manufacturers that export their products to more than 2000 customers worldwide, ABC Manufacturing Company needs to have an efficient and effective inventory management system in order to ensure that their operations can run smoothly as well as to ensure that their products can be shipped on time according to customers' request. Factory 21 of ABC Manufacturing Company is located in Klang, Malaysia. They produce latex and nitrile 
examination gloves. Factory 21 of ABC Manufacturing Company is chosen because the company is experiencing issues with managing the inventory.

\section{RESEARCH METHODOLOGY}

This study applied a qualitative research design. Thus, a virtual interview is conducted with the staff-in-charge. WHQuestions is prepared for the interview to identify the possible issues happening in the company and the possible causes causing the problems. During the interview session, the technique of observation was applied as well. After the interview session, the 5 Whys Analysis method was used to identify the issue's root cause. This approach allows one to ask how the sequential causes of an event of failure occurred and determine the path of cause-effect failure. The chosen respondent is a female whose age is between 30 to 40 years old. The interviewee has been working with the company for more than two years as an executive in the packing department. And therefore, the interviewee is in charge of the packing process of the products and the inventory record of the finished goods.

Through the 5 Whys Analysis, the main factor affecting the inventory inccacury in Factory 21 of ABC Manufacturing Company is identified. Due to the manual counting process, human error does sometimes happens. An automation system is then proposed in order to improve the inventory record inaccuracy. With the automation system, the manual labour which is the manual counting process is eliminated, resulting to an improvement in the inventory record accuracy.

\section{FINDINGS}

From the findings of 5 Whys Analysis, it shows that the cause of the problem is due to human error. Before keeping the pallet in the warehouse, workers will manually count the pallet's cartons after arranging them on the pallet. Then, pallet slip consisting of the pallet's information, which includes the quantity of the cartons, is generated. Due to this manual counting process, human error may sometimes occur. For instance, they accidentally miscount the number of cartons that are included on a pallet. As a result, the physical stock does not match the data they entered in the system, which they only realize about this issue when they want to recheck the inventory in the warehouse. At the end of the month, they will readjust the record according to the quantity of inventory they have. This action only helps in solving the problems at that moment but not in the long run.

Through the 5 Whys Analysis, the main reason behind the issue is identified. As the main reason behind the inventory record inaccuracy comes from human error, the frequency and the severity of the inventory record inaccuracy need to be determined. The data collected from the virtual interview analyzed before a solution to the issue is proposed. As a result, a sensor network system will be developed to automate the manual counting process. It is to eliminate human error due to human misconduct.

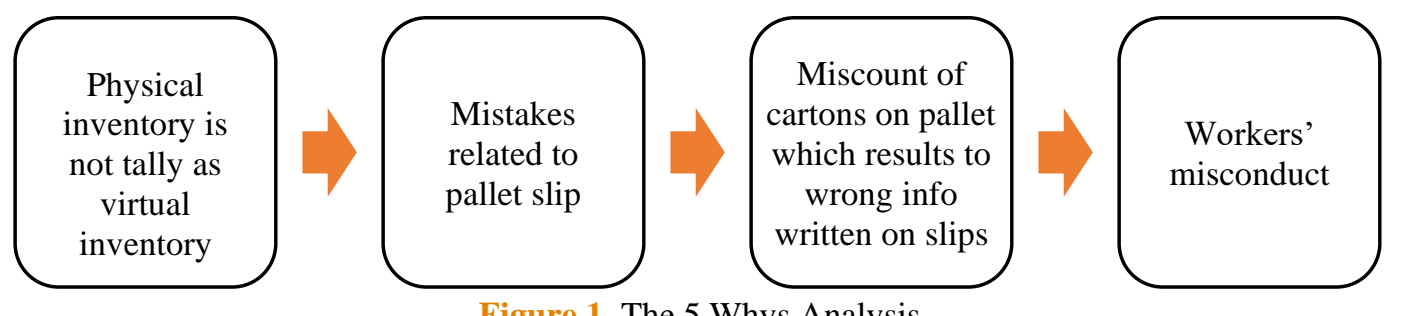

Figure 1. The 5 Whys Analysis

As shown in Table 1, Factory 21 of ABC Manufacturing Company faces severe inventory record inaccuracy when they receive the order at high to maximum capacity. This is due to the surge of demand in gloves during the early stages of Covid-19 as they receive 100\% more than the usual order starting from March 2020 (Palma, 2020; Reuters, 2020a). And in April 2020, the company has stepped up its factory utilization from $10 \%$ to $95 \%$ in order to meet the customer demand (Reuters, 2020a).

Table 1. Inventory Record Inaccuracy in Factory 21 of ABC Manufacturing Company

\begin{tabular}{lll}
\hline Month (in the year 2020) & Inventory Record Inaccuracy & Order Capacity \\
\hline January & Moderate & Moderate capacity \\
February & Moderate & Moderate capacity \\
March & Severe & Maximum capacity \\
April & Severe & Maximum capacity \\
May & Severe & Maximum capacity \\
June & Major & Maximum capacity \\
July & Severe & Maximum capacity \\
August & Moderate & High capacity \\
September & Minor & High capacity \\
October & Minor & Moderate capacity \\
November & Insignificant & Minimum capacity \\
\hline Notes: Inventory record inaccuracy 1- Insignificant; 2 - Minor; 3 - Moderate; 4 - Major; 5- Severe \\
Order capacity 1- None; 2- Minimum Capacity; 3- Moderate Capacity; 4 - High Capacity; 5- Maximum Capacity
\end{tabular}


The degree of the inventory record inaccuracy and the order capacity received by the factory is based on the 5-Point Likert Scale. For the inventory record inaccuracy, it is measured based on the frequency of the record inaccuracy which means that the more often cartons miscounting happened, the more severe the inventory record inaccuracy will be as the discrepancies between virtual and physical inventory will become bigger and adjustments of the inventory record will only be done at the end of the month. Starting from insignificant, which means that there is inventory record inaccuracy found out, followed by minor, moderate, major and severe. Inventory record inaccuracy is severe as every employee in the operation department need to be deployed to the warehouse to recount the inventory so that the physical inventory will match the virtual inventory recorded in the system.

As for the order capacity, the factory operates at the capacity which is defined by the number of orders received from the customers. Starting from the least value which is very low to none, followed by minimum capacity, the factory needs to reduce their production capacity to the minimum level as most of the workers are quarantined since the Covid-19 pandemic infects them. Then, followed by moderate capacity which is the standard capacity at which the factory operates before the Covid-19 pandemic era, high capacity and maximum capacity at which the factory already reached the maximum capacity of producing the products in a month. Due to the Covid-19 pandemic, there is a surge of demand in glove and the factory needs to operate at maximum capacity to meet the customer's demands. In order to do that, the factory also hires part-timers to increase their workforce capacity.

Figure 2 shows the flow of the packing process in Factory 21 of ABC Manufacturing Company. After the goods are produced and packed into a carton at the assembly line, the carton will be sealed and weighed at the packing station before it will pass through the metal detector. The carton will then be palletized by the worker before it is sealed with a stretch wrap film. Then, the worker in charge of generating the pallet slip will count the cartons on the pallet before generating the pallet slip and put it on the pallet for identification. Only then the pallet will be kept in the warehouse by the worker in charge of the warehouse. After that, the goods will either be shipped to the point of destination or will be brought back to the factory for repackaging.

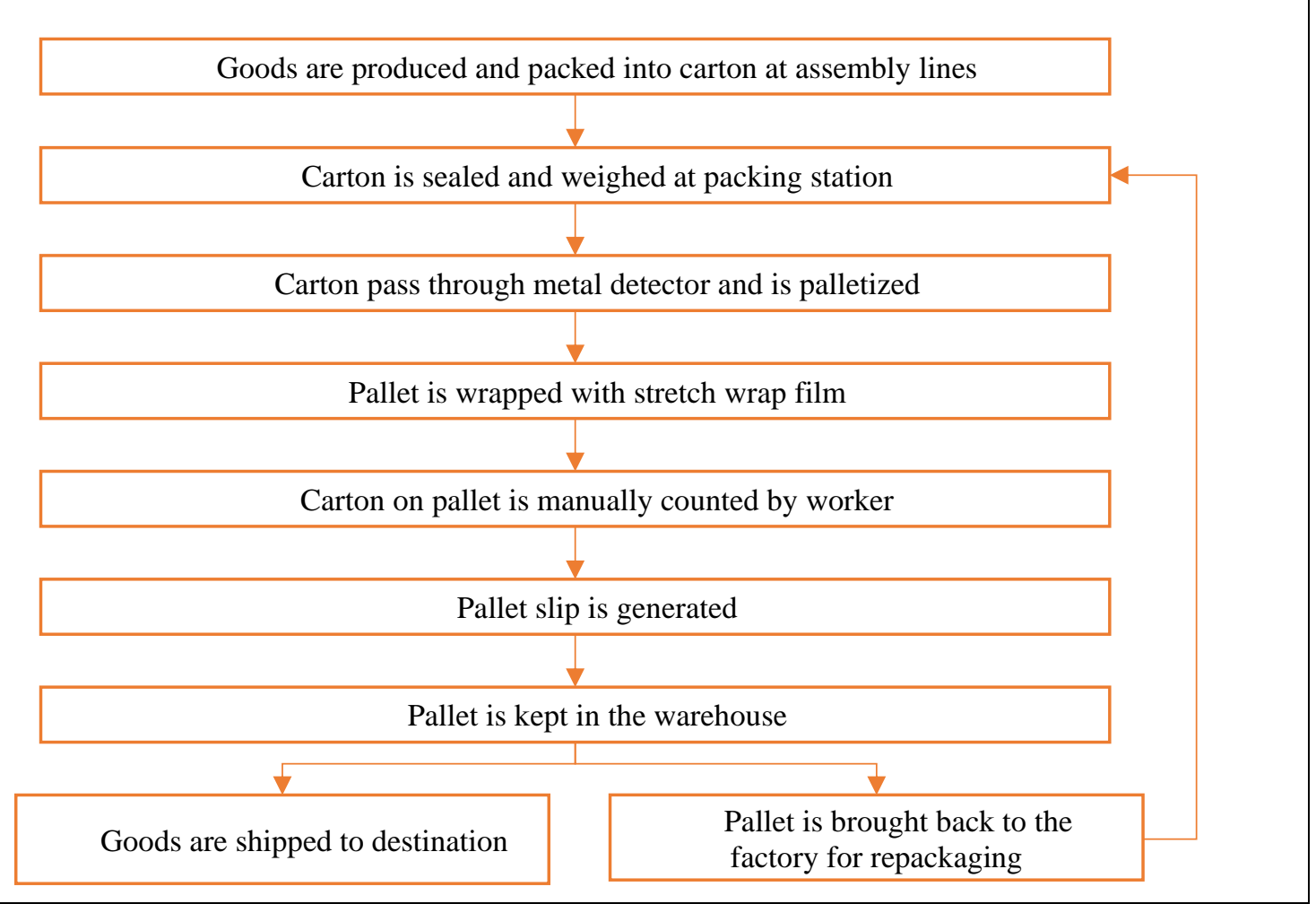

Figure 2. Flow chart of the packaging process in Factory 21 of ABC manufacturing company

There are three workers involved in this process. First worker is in-charged of sealing and weighing the carton and wrapping the pallet. The second worker is in-charged of counting the carton on the pallet and generating pallet slip consisting of the info of products on the pallet. The last worker is in-charged of keeping the pallet in the warehouse and taking the pallet from the warehouse.

The workplace cluster of Teratai Covid-19, which consists mainly of Klang's ABC Manufacturing Company workers has made 20 of the company's factories in Meru had to stop production temporarily, while another eight factories work at a capacity of just $10 \%-20 \%$. This is because about 3000 of those tested positive in November 2020, are ABC Manufacturing Company's workers. Around half of ABC Manufacturing Company's total production capacity is reflected by the 28 affected facilities in Meru (Reuters, 2020; Surendran, 2020). Thus, Factory 21 of ABC Manufacturing Company's production capacity is also affected as they can only produce at minimum capacity. And during this time, it 
can be seen that the inventory record inaccuracy in Factory 21 of ABC Manufacturing Company is insignificant since they produce the order at the minimum capacity. Nevertheless, this will not solve the inventory record inaccuracy problem as the same problem will arise when the production capacity is back at the maximum capacity. Therefore, counting error due to workers' misconduct needs to be eliminated to improve record accuracy.

Based on the data, a prototype of the Arduino sensor network system will be designed to automate the manual counting process. The system will be using Arduino Uno and Ultrasonic sensor, which consists of two elements, an emitter and a receiver, both of which are active. And this sensor uses ultrasonic sound waves to detect the object (Saxena et al., 2020). The Arduino Uno board is an ATmega328P based microcontroller board which has 14 digital input/output (I/O) pins, 6 of which can be used as PWM outputs, six analogue inputs, a $16 \mathrm{MHz}$ ceramic resonator (CSTCE16M0V53-R0), a USB link, a power jack, a reset button and an ICSP header. The microcontroller can be programmed on the Arduino IDE (Integrated Development Environment). And the Arduino coding to program Arduino microcontroller board is called sketch (Arduino, 2014). Figure 3 shows the top view and Figure 4 shows the bottom view of Arduino sensor network system consisting of Arduino Uno board, Ultrasonic sensor, Potentiometer and liquid-crystal display (LCD) screen. Figure 5 shows the circuit diagram of the arduino sensor network system

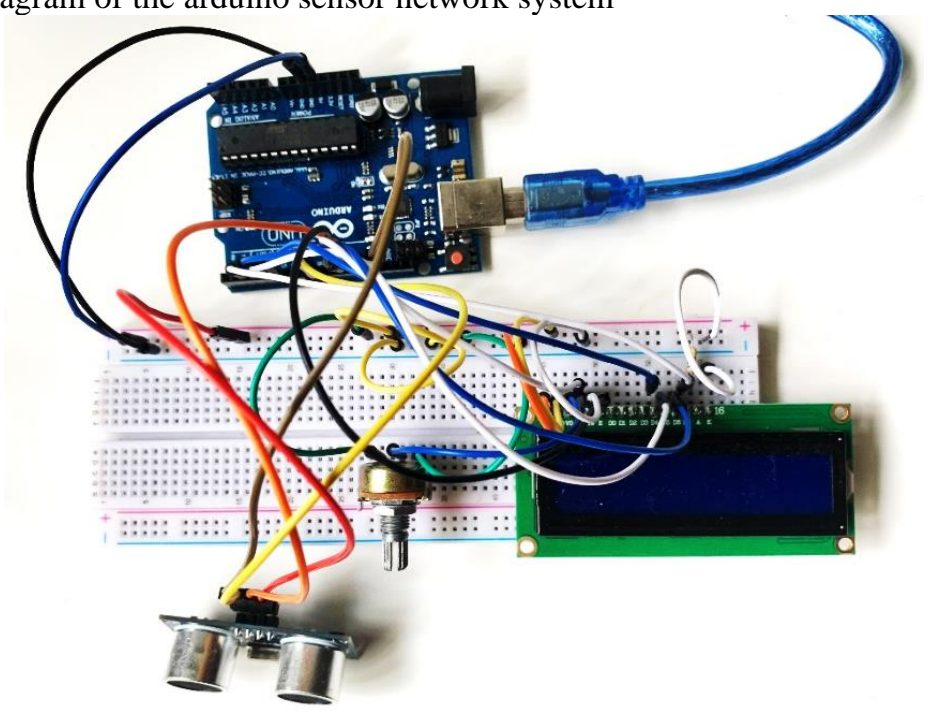

Figure 3. The top view of Arduino sensor network system consisting of Arduino Uno board, Ultrasonic sensor, Potentiometer and LCD screen

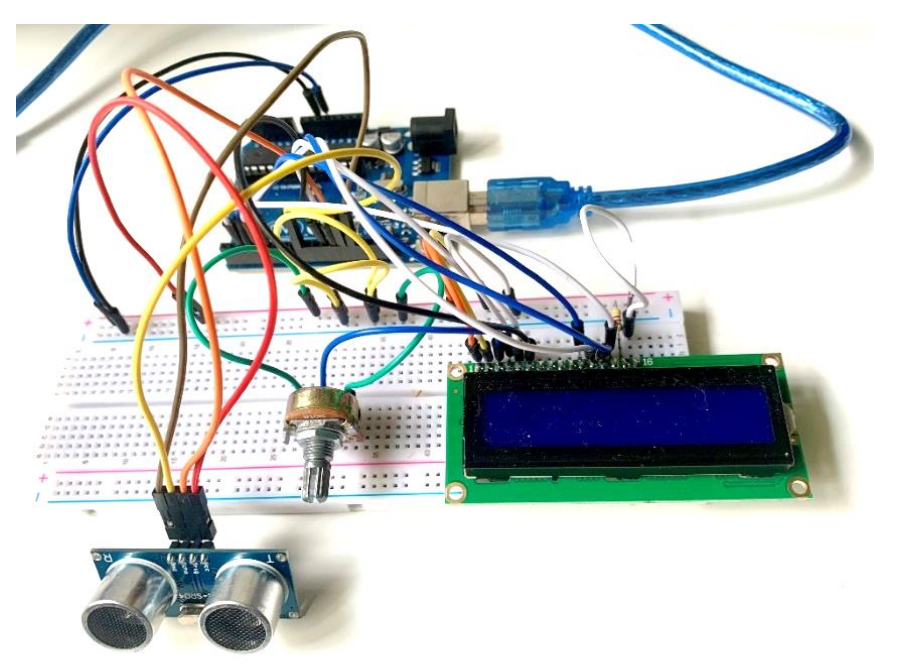

Figure 4. The bottom view of Arduino sensor network system consisting of Arduino Uno board, Ultrasonic sensor, Potentiometer and LCD screen 


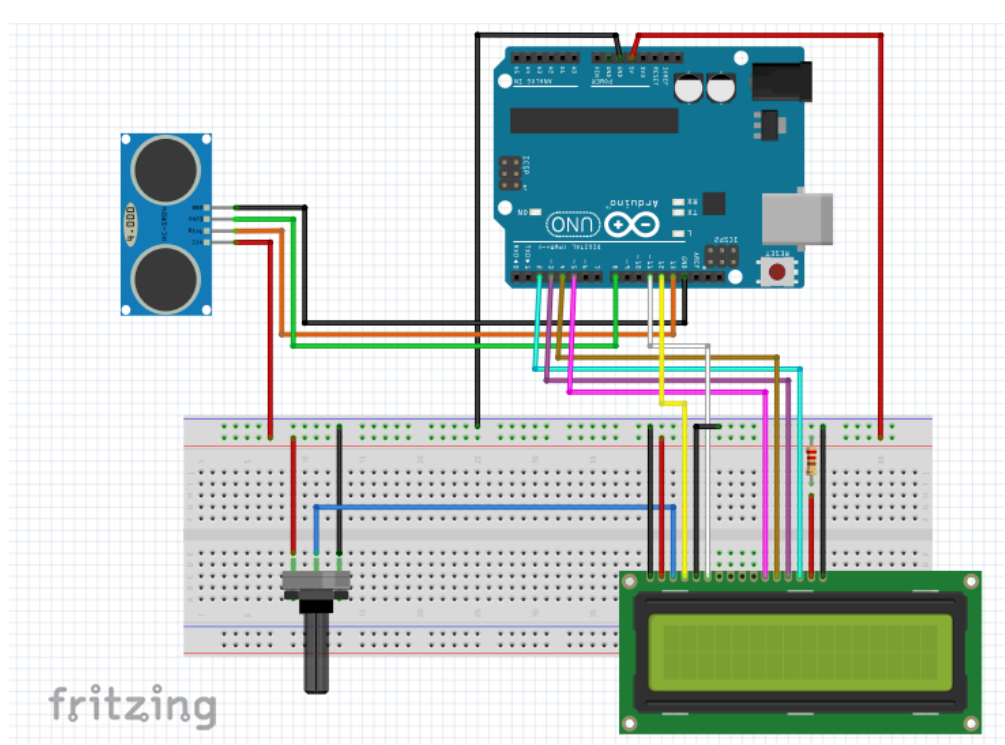

Figure 5. Circuit Diagram of Arduino Sensor Network System

The Arduino sensor network system of counting moving objects is supposed to be a smart system that can record information on how many items such as cartons have passed through the conveyor belt at the packing station before being arranged on a pallet. The data captured by the Ultrasonic sensor will determine the number of cartons that will be palletized. Through the ultrasonic sensor, the Arduino Uno board gets its input by collecting the captured data. The sensor consists of an emitter that emits ultrasonic sound waves and a detector that collects back-reflected rays. As the direction of these rays is disrupted by the carton, the sensor senses an approaching carton and transmits signals to the Arduino board. According to the manually written code in it, Arduino takes these analogue signals and works on them to program the Arduino board for the required operations. An Arduino is programmed by connecting the Arduino board with a device via its Arduino USB cable (Carvalho et al., 2016; Saxena et al., 2020). The processes create digital output, which recognizes the number of cartons passing through the conveyor belt. Such outputs are then sent to an LCD screen showing the number of cartons passing through the counter. The potentiometer in the circuit functions is to adjust the contrast of the LCD screen.

Using the ESP8266 WiFi Module, a self-contained SOC with an integrated TCP/IP protocol stack that enables your WiFi network to reach any microcontroller, the sensor data will be sent to a MySQL database. Data can then be accessed and visualized from anywhere around the world as the sensor readings, timestamp, and other information from the database will be displayed on a web page.

The whole process involved several sketches uploaded in Arduino Uno for the Arduino sensor network system. Liquid crystal library is included. Then, the trigger pin and echo pin of the ultrasonic is defined. Liquid crystal library is initialized, and variables for detecting changes in the state is defined. The following command is included.

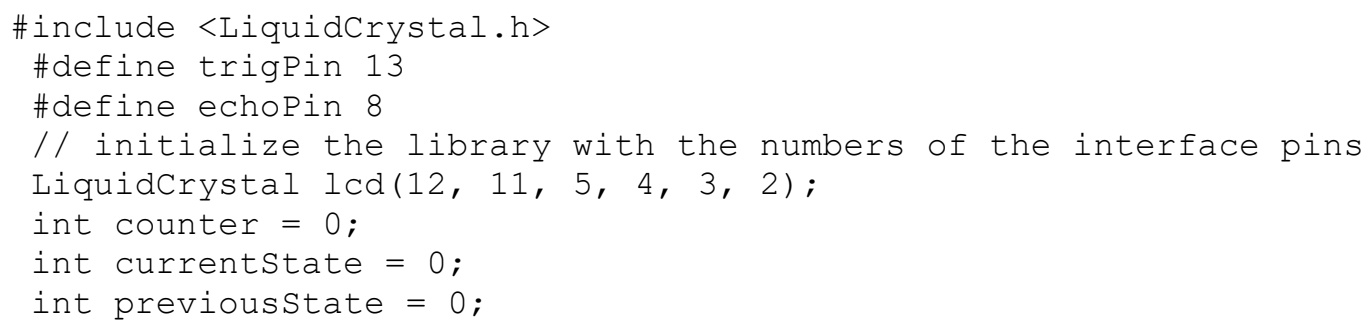

Pin mode for trigger pin and echo pin of the ultrasonic sensor is declared in the setup function. A cursor is set at coordinate $(4,0)$ and text "counter" is printed on the LCD screen. The following command is included.

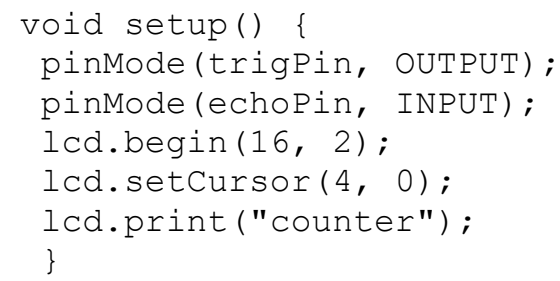


In the loop function, distance is determined. When there is any object comes within the range of $10 \mathrm{~cm}$, the current state will be equal to 1 or else the current state will be equal to 0 . And when the current state is equal to 1 , it will count 1 . LCD cursor is set to the second row to print the counting value. If the ultrasonic sensor detects the object within the range of $10 \mathrm{~cm}$, value is equal to 1 , and the counting value is printed on the LCD screen. If there is an increment of counting value when there is an object passing through the sensor and the sensor counting value is equal to the current state plus 1. The following command is included.

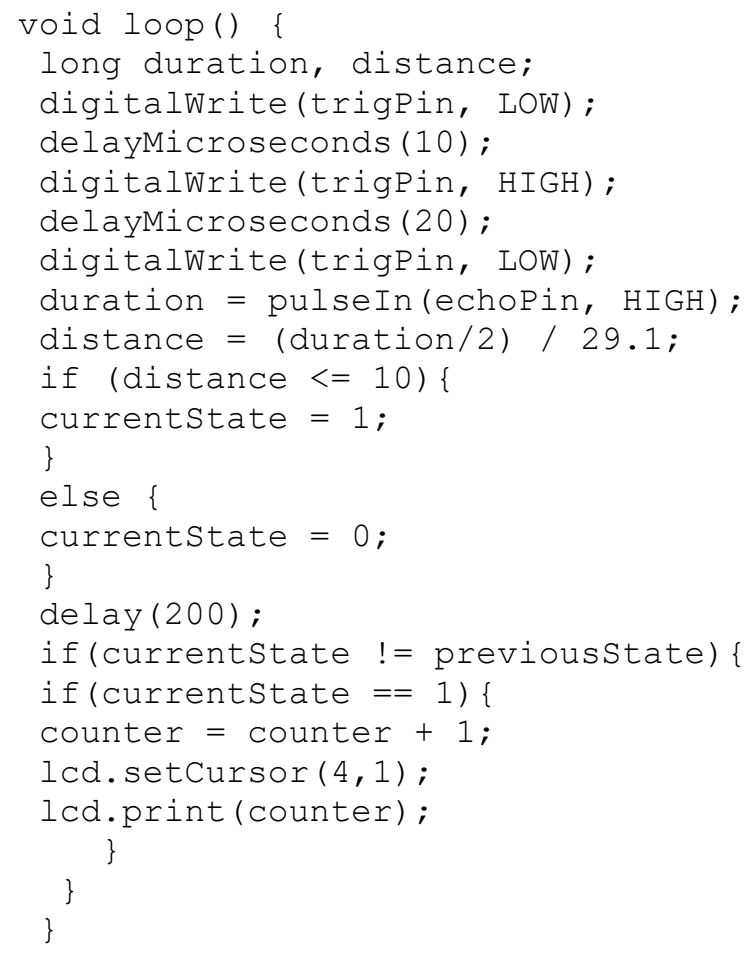

\section{DISCUSSION AND CONCLUSION}

Through the deployment of Arduino sensor network system, the issue faced by Factory 21 of ABC Manufacturing Company can be solved as physical carton counting process will be eliminated. Since the sensor data is displayed both on the LCD display screen and the web page, workers at the packing station and outside of the packing station can view the data. Besides that, the worker that is in charge of generating the pallet slip no longer need to go to the packing station to count the cartons and record the input manually before generating the pallet slip as the data can now be accessed remotely. This can also minimize transaction error as the manual data recording process is also eliminated. As a result, inventory accuracy can be improved.

Nevertheless, in order to differentiate between brands of cartons as well as product sizes stated on the cartons efficiently, an image recognition sensor will be required. This can be achieved with ESP32-CAM, which is a camera module to construct automation projects with video, photography and image recognition features. Next, the image of a new object needs to be registered and saved before it can detect the object later upon registration of the new item. Image recognition is a term used to describe a collection of algorithms and technologies that attempt to interpret images and recognize the hidden representations of the characteristics behind them and automatically apply these learned representations to various tasks, such as automatically classifying images into different categories, understanding which objects are present and where in an image, etc. To produce the requisite results for solving such problems, these technologies leverage different conventional computer vision approaches as well as machine learning and deep learning algorithms.

To conclude, the Arduino sensor network system can improve the inventory record accuracy as the manual counting process is automated. Besides that, data from the sensor network system can be viewed from the LCD display as well as remotely from the webpage and serial monitor that display the sensor data which will minimize transaction error as data is already computerized. In order to make the Arduino sensor network system works better in improving the inventory record accuracy, a camera module ESP32-CAM need to be included to the system to differentiate the cartons of different product brands and sizes. This does not only eliminate the human labour to count the cartons during the palletizing process but also will improve the efficiency of the product packing and palletizing process as the image recognition sensor will identify and classify the cartons based on the product sizes and brands stated on the cartons while the counting sensor counts the cartons that will be palletized. 


\section{LIMITATION AND RECOMMENDATION}

This study, however, is subject to several limitations. There is limited access to data as the manufacturing company does not keep the inventory record before making adjustments. They only keep the most current inventory record, which means after making adjustments to ensure that the physical and virtual inventory matches, they no longer have the access to their previous inaccurate data. Therefore, the severity of the data discrepancies of physical and virtual inventory could not be quantified. Nevertheless, the severity of the inventory inaccuracy is determined by the frequency in finding the inventory record discrepancies as well as the frequency of adjustments made in a month.

Time limitation is the main constraint of this study in developing an Arduino sensor network system which includes WiFi module ESP8266. Therefore, future research should focus on establishing a database system to store the data as well as to display the sensor data captured by Arduino Uno. Only then the data can be accessed and visualized from anywhere around the world as the sensor readings, timestamp and other information from the database will be displayed on a web page. Besides that, the installation of the camera module ESP32-CAM to the system is required to differentiate the cartons of different product brands and sizes. The camera module will be used as an image recognition sensor to identify and classify the cartons based on the product sizes and brands stated on the cartons. This can further improve the efficiency of the product packing and palletizing process as human labour is eliminated.

Apart from that, future studies may also include LoRa shield in the sensor network system as long range (LoRa) shield allows the user to transmit data at low data rates and cover incredibly long ranges. It enables connectivity with ultra-longrange spectrum distribution and high sensitivity to interference while reducing current usage. LoRa shield is perfect for Internet of Things (IoT) projects as two LoRa devices with a proper antenna can exchange data over a long-distance using $\mathrm{RF}$ signals in point-to-point communication, unlike WiFi or Bluetooth that supports only short distance communication. This is useful, for instance, for exchanging data between two ESP32 boards equipped with LoRa transceiver chips that are relatively far from each other or in Wi-Fi-free environments.

Nevertheless, ethics and good governance could be one of the contributing factors affecting the inventory record accuracy in Factory 21 of ABC Manufacturing Company. In order to maintain an accurate record, proper record management is required to prevent alteration of data. For instance, if a worker takes the goods from the warehouse, but he fails to record the transaction in the system due to misconduct or lack of accountability and integrity in oneself, this could affect the accuracy of the inventory record. Hence, the company need to have a system whereby the goods going in and out must be recorded in a transparent and systematic manner. Therefore, a company needs to have World-class good governance ethics to ensure transparency of data and integrity and accountability of employees in the company as proposed by Wan Husain (2020).

\section{ACKNOWLEDGEMENT}

The authors would like to thank UMP.

\section{REFERENCES}

Arduino. (2014). Arduino UNO Rev3. In Arduino (Vol. 328, pp. 1-7). https://store.arduino.cc/usa/arduino-uno-smd-rev3\%0A

Atnafu, D., \& Balda, A. (2018). The impact of inventory management practice on firms' competitiveness and organizational performance: Empirical evidence from micro and small enterprises in Ethiopia. Cogent Business \& Management, 5(1), 1-16. https://doi.org/10.1080/23311975.2018.1503219

Buntak, K., Kovačić, M., \& Mutavdžija, M. (2019). Internet of things and smart warehouses as the future of logistics. Tehnički Glasnik, 13(3), 248-253. https://doi.org/10.31803/tg-20190215200430

Carvalho, B. F., Silva, C. C. M., Silva, A. M., Buiati, F., \& Timóteo, R. (2016). Evaluation of an arduino-based IoT person counter. IoTBD 2016 - Proceedings of the International Conference on Internet of Things and Big Data, IoTBD, 129-136. https://doi.org/10.5220/0005954601290136

Chuang, H. H. C., \& Oliva, R. (2015). Inventory record inaccuracy: Causes and labor effects. In Journal of Operations Management (Vols. 39-40, pp. 63-78). https://doi.org/10.1016/j.jom.2015.07.006

Dai, H., Li, J., Yan, N., \& Zhou, W. (2016). Bullwhip effect and supply chain costs with low-and high-quality information on inventory shrinkage. European Journal of Operational Research, 250(2), 457-469.

Department of Statistics Malaysia. (2020). Monthly Manufacturing Statistics Malaysia, September 2020. In Department of Statistics Malaysia Official Portal. https://www.dosm.gov.my/v1/index.php?r=column/cthemeByCat\&cat=90\&bul_id=cmhRVFBDelZYWiszaklaS0Nkcll1QT09 \&menu_id=SjgwNXdiM0JIT3Q2TDBIWXdKdUVldz09

Drakaki, M., \& Tzionas, P. (2019). Investigating the impact of inventory inaccuracy on the bullwhip effect in RFID-enabled supply chains using colored petri nets. Journal of Modelling in Management, 14(2), 360-384. https://doi.org/10.1108/JM2-08-20170081

Hachem, W. E. L., Harik, R., \& Khoury, J. (2016). Error Generation, Inventory Record Inaccuracy (IRI) and Effects on Performance: A Dynamic Investigation. Product Lifecycle Management for Digital Transformation of Industries. IFIP Advances in Information and Communication Technology, 642-651.

Karim, N. A., Nawawi, A., \& Salin, A. S. A. P. (2018). Inventory Control Weaknesses - A Case Study of Lubricant Manufacturing Company. Journal of Financial Crime, 34(1), 1-5.

Mohamad, S. J. A. N. bin S., Suraidi, N. N., Rahman, N. A. A., \& Suhaimi, R. D. S. R. (2016). A Study on Relationship between Inventory Management and Company Performance: A Case Study of Textile Chain Store. Journal of Advanced Management Science, 4(4), 299-304. https://doi.org/10.12720/joams.4.4.299-304

Okyay, H. K. (2014). Detailed Inventory Record Inaccuracy Analysis. 
Prempeh, K. B., \& Amankona, G. P. (2020). Does Working Capital Management Affect Profitability of Ghanaian Manufacturing Firms? Zagreb International Review of Economics \& Business, 23(1), 1-18. https://doi.org/10.2478/zireb-2020-0001

Qin, W., Zhong, R. Y., Dai, H. Y., \& Zhuang, Z. L. (2017). An assessment model for RFID impacts on prevention and visibility of inventory inaccuracy presence. Advanced Engineering Informatics, 34(September), 70-79. https://doi.org/10.1016/j.aei.2017.09.006

Rekik, Y., Syntetos, A. A., \& Glock, C. H. (2019). Inventory Inaccuracy in Retailing: Does it Matter? https://www.cardiff.ac.uk/_data/assets/pdf_file/0003/1729236/84486-ECR-Inventory-Inaccuracy-Report-v12.pdf

Reuters. (2020). Malaysia to shut some Top Glove factories in phases amid COVID-19 outbreak. In Channel News Asia. https://www.channelnewsasia.com/news/business/covid-19-malaysia-top-glove-close-factories-in-stages-outbreak-13621788

Saxena, A., Taterh, S., \& Saxena, N. (2020). Comparative Study of the Ultrasonic and Infrared Person Counter. Advances in Intelligent Systems and Computing, 1154, 1081-1092. https://doi.org/10.1007/978-981-15-4032-5_96

Sowmya, T. K., Agadi, S. V, Saraswathi, K. G., Nirvani, P. B., \& Prajwal, S. (2018). Implementation of IoT Based Smart Warehouse Monitoring System. 6(15), 1-4. http://oatd.org/oatd/record?record=\%22handle:10393/37756\%22

Sunday, O., \& Joseph, E. E. (2017). Inventory Management and SMEs Profitability . A Study of Furniture Manufacturing, Wholesale and Eatery Industry in Delta State , Nigeria. Journal of Finance and Accounting, 5(3), 75-79. https://doi.org/10.12691/jfa-5-31

Surendran, S. (2020, December). Covid-19 cuts Top Glove both ways. The Edge Malaysia.

Talavera, H. E., Banks, J., Smith, N. R., \& Cárdenas-Barrón, L. E. (2015). Enhancing the management of shared inventory in the steel industry using RFID: an alternative to bar codes. International Journal of Machine Learning and Cybernetics, 6(5), $733-745$. https://doi.org/10.1007/s13042-015-0406-x

Tejesh, B. S. S., \& Neeraja, S. (2018). Warehouse inventory management system using IoT and open source framework. Alexandria Engineering Journal, 57(4), 3817-3823. https://doi.org/10.1016/j.aej.2018.02.003

The Edge Markets. (2020). Malaysian manufacturing sector pessimistic in projections on business prospects for rest of 2020 - FMM. Malaysia.

Top Glove Corporation Berhad. (2020). Top Glove Corporation Berhad | Corporate Profile. In Top Glove Corporation Berhad. https://www.topglove.com/corporate-profile/

Velasco, J., Alberto, L., Ambatali, H. D., Canilang, M., Daria, V., Liwanag, J. B., \& Madrigal, G. A. (2019). Internet of things-based (IoT) inventory monitoring refrigerator using arduino sensor network. Indonesian Journal of Electrical Engineering and Computer Science, 18(1), 508-515. https://doi.org/10.11591/ijeecs.v18.i1.pp508-515

Wan Husain, W. A. F. (2020). Insights: the Conceptual Framework for Buiding the World Class Good Governance Ethics. Journal of Governance and Integrity, 4(1), 1-5. https://doi.org/10.15282/jgi.4.1.2020.5606

Yerpude, S., \& Singhal, T. K. (2018). SMART Warehouse with Internet of Things supported Inventory Management System. International Journal of Pure and Applied Mathematics, 118(24), 1-15.

\section{CONFLICT OF INTEREST}

The author(s), as noted, certify that they have NO affiliations with or involvement in any organization or agency with any financial interest (such as honoraria; educational grants; participation in speakers' bureaus; membership, jobs, consultancies, stock ownership, or other equity interest; and expert testimony or patent-licensing arrangements), or nonfinancial interest (such as personal or professional relationships, affiliations, expertise or beliefs) in the subject matter or materials addressed in this manuscript.

\section{AUTHORS' BIOGRAPHY}

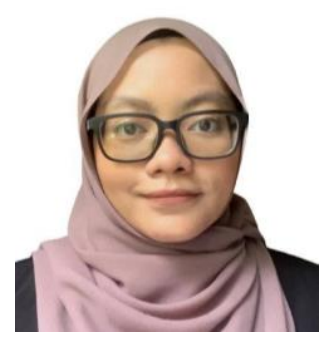

Author's Full Name: Iman Haddad Qaisara Dhia, Mohd Mahzan

Author's Email: qysaradhia@gmail.com

Author Professional Bio: Iman Haddad Qaisara Dhia Mohd Mahzan is a final year student of Bachelor of Business Engineering (Hons.) in Faculty of Industrial Management (FIM), Universiti Malaysia Pahang (UMP). 


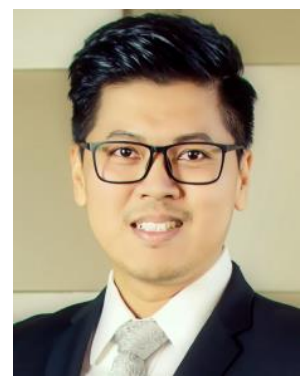

Author's Full Name: Khai Loon, Lee

Author's Email: leekhailoon@ump.edu.my

Author Professional Bio: Ts. Dr. Lee Khai Loon is a Senior Lecturer in the Faculty of Industrial Management (FIM), Universiti Malaysia Pahang (UMP). He specialized in supply chain management, technology management, operation management, industrial engineering, and business management. He holds a Doctor of Philosophy (Ph.D.) in Supply Chain Management and a Bachelor Degree in Technology Management from the School of Technology Management and Logistics, Universiti Utara Malaysia (UUM). He has a long industrial experience and teaching undergraduate and postgraduate students in the university. He is a chartered member of The Chartered Institute of Logistics and Transport (CMILT) Malaysia and UK, the Professional Technologist in Malaysia Board of Technologists (MBOT), the Certified Trainer (TTT) by HRDF, the Certified Trainer for MonsoonSIM, and Mendeley Advisor. 